ISSN 1808-3765

\title{
DESEMPENHO AGRONÔMICO DE CULTIVARES DE CEBOLA SOB DIFERENTES MANEJOS DE IRRIGAÇÃO NO SUBMÉDIO SÃO FRANCISCO
}

\section{GEORGE RICARDO LIBÓRIO BANDEIRA ${ }^{1}$; SÉRGIO OLIVEIRA PINTO DE QUEIROZ $^{2}$; CARLOS ALBERTO ARAG ÃO ${ }^{2}$; NIVALDO DUARTE COSTA ${ }^{3}$ E CARLOS ANTÔNIO FERNADES SANTOS ${ }^{3}$}

${ }^{1}$ Engenheiro Agrônomo, Empresa Baiana de Desenvolvimento Agrícola, Pça. Imaculada Conceição, 20, CEP: 48903-490, Juazeiro, BA, Brasil.

${ }^{2}$ Professor Titular, Departamento de Tecnologia e Ciências Sociais, UNEB, Av. Edgard Chastinet, s/n, Bairro São Geraldo, CEP: 48900-000, Juazeiro, BA, Brasil, e-mail: sopqueiroz@gmail.com

${ }^{3}$ Pesquisador, Embrapa Semiárido, CEP: 56302-970, Petrolina, PE, Brasil.

\section{RESUMO}

Este trabalho teve o objetivo de estudar o desenvolvimento de cinco cultivares de cebola (IPA 10, IPA 11, Alfa São Francisco, Serena e Antares), no município de Juazeiro, BA, irrigadas por gotejamento, sob quatro métodos de manejos de irrigação: Penman - Monteith FAO, tensiometria, e $100 \%$ e $70 \%$ da evaporação do tanque classe A. O delineamento estatístico utilizado foi o inteiramente casualizado, em esquema de parcelas subdivididas, constituídos de quatro manejos de irrigação nas parcelas e cinco cultivares de cebola nas subparcelas. Foram avaliadas a produtividade total, produtividade comercial, produtividade de bulbos classe 1, 2, 3 e 4, teor de ácido pirúvico e teor de sólidos solúveis. Não foi observado efeito de interação entre os manejos de água e as cultivares de cebolas. As cultivares Serena e Antares apresentaram produtividade total e comercial significativamente superior às demais cultivares. O manejo de irrigação baseado no Tanque Classe A a 70\% promoveu desempenho inferior para a variável produtividade comercial.

Palavras-chave: Allium cepa L., evapotranspiração, manejo de água.

\section{ABSTRACT}

\author{
BANDEIRA, G. R. L.; DE QUEIROZ, S. O. P.; ARAGÃO, C. A.; COSTA, N. D.; \\ SANTOS, C. A. F. \\ CROP PERFORMANCE OF ONION CULTIVARS UNDER DIFFERENT \\ IRRIGATION MANAGEMENTS IN THE LOWER SÃO FRANCISCO BASIN
}

This work aimed to study the development of five onion cultivars (IPA 10, IPA 11, Alfa São Francisco, Serena and Antares), in Juazeiro, State of Bahia, Brazil, drip irrigated, under four methods of irrigation management: Penman - Monteith FAO, tensiometry, $100 \%$ and $70 \%$ of class A pan evaporation. The experimental design was completely randomized, in a split-plot design, consisting of four irrigation management methods in the plots and five onion cultivars in the subplots. The variables evaluated were: total yield, marketable yield, yield of type 1, 2, 3 and 4 bulbs, pyruvic acid content and soluble solids content. There was no interaction effect between irrigation management methods and the onion cultivars. The yield and quality of Serena and Antares cultivars were significantly higher than the ones of the other cultivars. 
The irrigation management based on class A pan at 70\% resulted in a lower performance for the variable marketable yield.

KEYWORDS: Allium cepa L., evapotranspiration, water management.

\section{INTRODUÇÃO}

A região do Vale do Submédio São Francisco, no Nordeste brasileiro, destaca-se como uma das principais produtoras de cebola no Brasil. Apresenta área plantada de aproximadamente 4.500 ha e produtividade média superior a 23 ton.ha $^{-1}$, sendo as principais cultivares exploradas a do tipo amarela Vale Ouro IPA-11, Brisa IPA-12 e Alfa São Francisco, esta última desenvolvida para o segundo semestre do ano, além da roxa Franciscana IPA-10, cultivadas predominantemente com o método de irrigação superficial.

A região tem verificado a expansão da área sob produção de cebola irrigada por gotejamento, tecnologia que permite a obtenção de elevadas produtividades e melhoria na qualidade do produto, se associada ao uso de material genético superior; contudo, a produção regional se caracteriza como atividade típica de pequenas e médias propriedades de natureza familiar, dificultando a adoção de tecnologias que associam a elevação da produtividade à sustentabilidade ambiental, a exemplo do manejo da irrigação.

Para o manejo da irrigação, o uso de métodos indiretos, como do tanque classe A, tem boa aceitação, determinando a evapotranspiração de referência (ETo), sendo considerado como confiável por Fernandes (2008). A equação proposta por Penman, modificada por Monteith e, após novas modificações, passou a ser denominada de Penman-Monteith FAO, sendo então recomendada como padrão pela $\mathrm{FAO}$, uma vez que considera um maior número de parâmetros climatológicos para determinação indireta da evapotranspiração de referência (Doorenbos \& Kassam, 2000).

Alternativamente, o manejo da irrigação pode basear-se na medida da tensão de água no solo, adotando-se a tensiometria que funciona adequadamente na faixa de potencial entre 0 e - $80 \mathrm{kPa}$, indicada, portanto, para o manejo da irrigação na maioria das olerícolas (Marouelli, 2008). Marouelli (2007) afirma que para olerícolas, quando irrigadas por gotejamento, o potencial matricial não deve estar abaixo de $-40 \mathrm{kPa}$, em razão do sistema não molhar a parte aérea das plantas e de molhar somente fração do solo.

Este experimento teve por objetivo avaliar o comportamento de cinco cultivares de cebolas irrigadas por gotejamento, sob quatro manejos de água de irrigação, na região do Submédio São Francisco.

\section{MATERIAL E MÉTODOS}

O experimento foi conduzido no Departamento de Tecnologia e Ciências Sociais, DTCS, da Universidade do Estado da Bahia (UNEB), no município de Juazeiro - BA, a $9^{\circ}$ 25'10" latitude sul e 40²9'16" longitude oeste, sob altitude de $367 \mathrm{~m}$. O clima, segundo a classificação de Köeppen-Geiger, é do tipo semi-árido (BSwh), com valores médios anuais de precipitação de $542 \mathrm{~mm}$, temperatura de $28^{\circ} \mathrm{C}$ e umidade relativa do ar de $65 \%$.

$\mathrm{O}$ delineamento estatístico adotado foi o inteiramente casualizado, em esquema de parcelas subdivididas, constituídos de quatro manejos de irrigação nas parcelas e cinco cultivares de cebola nas subparcelas. Foi utilizado tubo gotejador com diâmetro nominal de 
$16 \mathrm{~mm}$, com emissores espaçados em $30 \mathrm{~cm}$ e vazão nominal de $1,3 \mathrm{~L} \cdot \mathrm{h}^{-1}$, sob pressão de serviço em 1 bar. Adotou-se espaçamento entre linhas de irrigação em 0,4 m, dispostos em uma bancada de $0,8 \mathrm{~m}$ de largura.

A reposição de água referente aos manejos de irrigação foi determinada pela equação de Penman-Montheith FAO; por tensiometria, adotando o potencial matricial crítico em -30 $\mathrm{kPa}$, como estabelecido por Marouelli (2007) e Enciso et al. (2009); e por $100 \%$ e $70 \%$ da evaporação do tanque classe A doravante denominados respectivamente como M1, M2, M3 e M4. As cultivares avaliadas foram a Franciscana IPA-11, Vale Ouro IPA-10, Alfa São Francisco, Serena e Antares, doravante denominadas respectivamente como C1, C2, C3, C4 e C5. A diferenciação dos métodos ocorreu a partir dos trinta dias após o transplantio, sendo até então a irrigação baseada em $100 \%$ da evaporação do tanque classe A para todos os tratamentos.

As mudas de cebola foram produzidas em sementeira localizada na Estação Experimental de Mandacaru, pertencente à Embrapa Semiárido, em Juazeiro - BA, sendo transplantadas para local definitivo aos 46 dias após a semeadura. $\mathrm{Na}$ adubação de plantio em sementeira, foram utilizados 80 g.m $\mathrm{m}^{-2}$ do adubo formulado 6-24-12, e 20 g.m $\mathrm{m}^{-2}$ de uréia na adubação de cobertura.

No local do cultivo definitivo, foram utilizados $200 \mathrm{Kg}^{-h a}{ }^{-1}$ da fórmula 6-24-12 na adubação de plantio. Na adubação em cobertura, aplicada via fertirrigação, utilizou-se 305 Kg.ha ${ }^{-1}$ de uréia ( $45 \%$ de N), $102 \mathrm{Kg}$ ha $^{-1}$ de nitrato de potássio $\left(60 \%\right.$ de $\mathrm{K}_{2} \mathrm{O}$ e $13 \%$ de $\left.\mathrm{N}\right)$ e $151 \mathrm{Kg} \cdot \mathrm{ha}^{-1}$ de sulfato de magnésio $\left(9 \%\right.$ de $\left.\mathrm{MgSO}_{4}\right)$, parcelados em 10 aplicações.

A interpretação e as adubações seguiram as recomendações preconizadas no Manual de Adubação e Calagem do Estado da Bahia (1989), para a cultura da cebola.

$\mathrm{A}$ análise química do solo do experimento apresentou os seguintes resultados: $\mathrm{pH}$ $\left(1: 2,5 \mathrm{H}_{2} \mathrm{O}\right)=8,1 ; \quad \mathrm{K}^{+}=0,44 \mathrm{cmol}_{\mathrm{c}} / \mathrm{dm}^{3} /$ T.F.S.A; $\mathrm{P}=83,1 \mathrm{mg} / \mathrm{dm}^{3} ; \mathrm{Ca}=4,9$ $\mathrm{cmol}_{\mathrm{c}} / \mathrm{dm}^{3} /$ T.F.S.A; $\mathrm{Mg}=1,1 \mathrm{cmol}_{\mathrm{c}} / \mathrm{dm}^{3} /$ T.F.S.A; $\mathrm{Na}=0,02 \mathrm{cmol}_{\mathrm{c}} / \mathrm{dm}^{3} /$ T.F.S.A; $\mathrm{H}+\mathrm{Al}=0,00$ $\mathrm{cmol}_{\mathrm{c}} / \mathrm{dm}^{3} /$ T.F.S.A; Al =0,0 \% M.O. $=0,96 ; \mathrm{T}=6,46 ; \mathrm{V} \%=100,00$. O solo foi classificado como Neossolo flúvico, cuja análise textural apresentou composição granulométrica com $85,5 \%$ de areia, $10,6 \%$ de silte e $3,9 \%$ de argila, cuja densidade foi determinada em 1,51 $\mathrm{kg} . \mathrm{dm}^{-3}$, estabelecendo uma porosidade total de $43 \%$.

Para o manejo M1, sob aplicação de $100 \%$ da ETo, determinou-se a evapotranspiração de referência através da equação de Penman - Monteith FAO, como descrito em Doorenbos \& Kassam (2000), com dados obtidos da estação automática do INMET Petrolina, distando $5,2 \mathrm{Km}$ da área do experimento.

No manejo M2, a curva de retenção de água no solo foi determinada correlacionandose a umidade com a tensão de água no solo. Assim, foram instalados quatro tensiômetros na profundidade de $20 \mathrm{~cm}$, em uma área de $1 \mathrm{~m}^{2}$, previamente saturada. Foram então iniciadas as leituras de tensão por meio de um tensímetro digital de punção inserido nos tensiômetros, e coletadas amostras de solo com o auxílio de um trado para a determinação do teor de água pelo método gravimétrico (secagem em estufa a $105^{\circ} \mathrm{C}$ até peso constante), por meio de balança com precisão de $0,01 \mathrm{~g}$. Esses dados foram utilizados a elaboração da curva de retenção de água no solo, obtida a partir de uma equação exponencial (Figura 1), com valores iniciais de tensão em - $10 \mathrm{KPa}$ (capacidade de campo- Cc) até a tensão de - $50 \mathrm{kPa}$. 


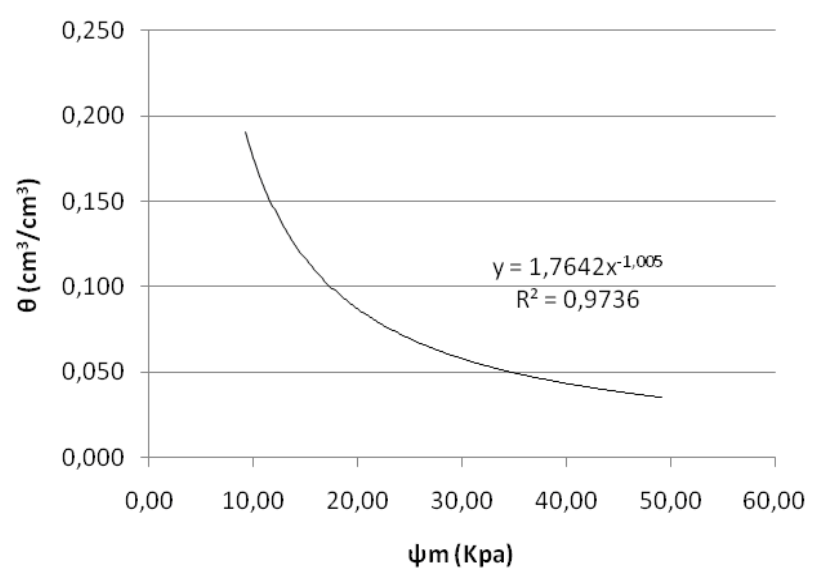

Figura 1. Curva de retenção de água de Neossolo flúvico, obtida por tensiometria, para a camada de $0-20 \mathrm{~cm}$.

Para o manejo por tensiometria (M2), em local definitivo após o transplantio das mudas, foram instalados três baterias de tensiômetros na profundidade de $20 \mathrm{~cm}$, para indicar o momento da irrigação e de $40 \mathrm{~cm}$, para detectar possíveis processos de percolação. A tensão inicial adotada foi a de $-10 \mathrm{kPa}$, correspondente à $\mathrm{Cc}$ e a de reposição em $-30 \mathrm{kPa}$, estabelecida como tensão limite. O preparo e instalação dos tensiômetros foram realizados como descrito por Marouelli (2008).

Nos manejos M3 e M4, determinou-se a ETo baseada na evaporação do tanque classe A, adotando-se respectivamente percentuais de $100 \%$ e $70 \%$ de reposição de água, obtidos da Estação Meteorológica da UNEB/DTCS, em coletas diárias. Para tanto, foi utilizada a metodologia sugerida por Doorembos \& Kasam (2000).

Foi utilizada a metodologia descrita por Keller \& Karmeli (1975), para a determinação do coeficiente de uniformidade em irrigação localizada (CUIL). O manejo cultural da cebola seguiu as recomendações de plantio para a região, sendo a colheita das plantas realizada noventa dias após o transplantio para os tratamentos M1, M2 e M3 e cento e cinco dias para o tratamento M4. Foram avaliadas as seguintes características: produtividade total, produtividade comercial, produtividade de bulbos, produção de bulbos com classificação em caixa 1,2, 3 e 4, teor de ácido pirúvico e teor de sólidos solúveis totais.

Para classificação de bulbos seguiu-se os critérios da portaria 529/18.03.95 do MAA (HORTIBRASIL, 2009).

A determinação da pungência e do teor de sólidos solúveis totais (SST), expresso em Brix $^{0}$, foi feita a partir da amostra de três bulbos pertencentes ao mesmo tipo de classe, retirados de cada subparcela e enviada para análise no laboratório de pós-colheita da Embrapa Semiárido. Para a pungência, determinou-se o conteúdo de ácido pirúvico utilizando-se a metodologia adaptada de Schwimmer \& Weston (1961), enquanto que para o teor de sólidos solúveis totais a quantificação foi realizada pelo uso do refratômetro manual.

A análise estatística dos resultados foi realizada por meio da análise de variância e comparação de médias de tratamentos entre si pelo teste de Tukey a 5\% de probabilidade. 


\section{RESULTADOS E DISCUSSÃO}

As lâminas brutas totais, apresentadas na Tabela 1, para os manejos M1, M2, M3 e M4, totalizaram, respectivamente, $463,47 \mathrm{~mm}, 535,63 \mathrm{~mm}, 483,49 \mathrm{~mm}$ e 418,68 mm. Para os métodos de manejo da irrigação baseados na estimativa da evapotranspiração, adotou-se frequência diária, enquanto para a tensiometria os eventos de irrigação basearam-se na ocorrência do potencial matricial crítico estabelecido em -30 kPa. Os valores encontrados para os manejos M1, M3 e M4 correspondem, respectivamente, a 86,53\%, 90,27\% e 78,17\% daqueles obtidos no manejo de irrigação M2. Quando se compara o manejo de irrigação M3 com o M4, verifica-se um consumo de água de $81,92 \%$ deste em relação ao primeiro, à partir da diferenciação dos manejos. No entanto, quando é feita a comparação do manejo M3 com o M1, considerado como referência, o percentual verificado é de $96 \%$ deste em relação ao primeiro, o que indica um bom desempenho do M3. Comparando métodos para determinação da evapotranspiração de referência em Boa Vista - RR e utilizando como padrão o método Penman-Monteith FAO, Araújo et al. (2007) encontraram uma boa correlação deste último com os valores obtidos com o tanque classe A, fato também observado no presente trabalho, comportamento semelhante ao observado por Mendonça et al., (2006) em Campo dos Goitacazes - RJ. Avaliando manejos de irrigação na cultura do milho, Resende \& Oliveira (2005) encontraram maiores produtividades para os métodos Penman-Monteith FAO e tanque classe A.

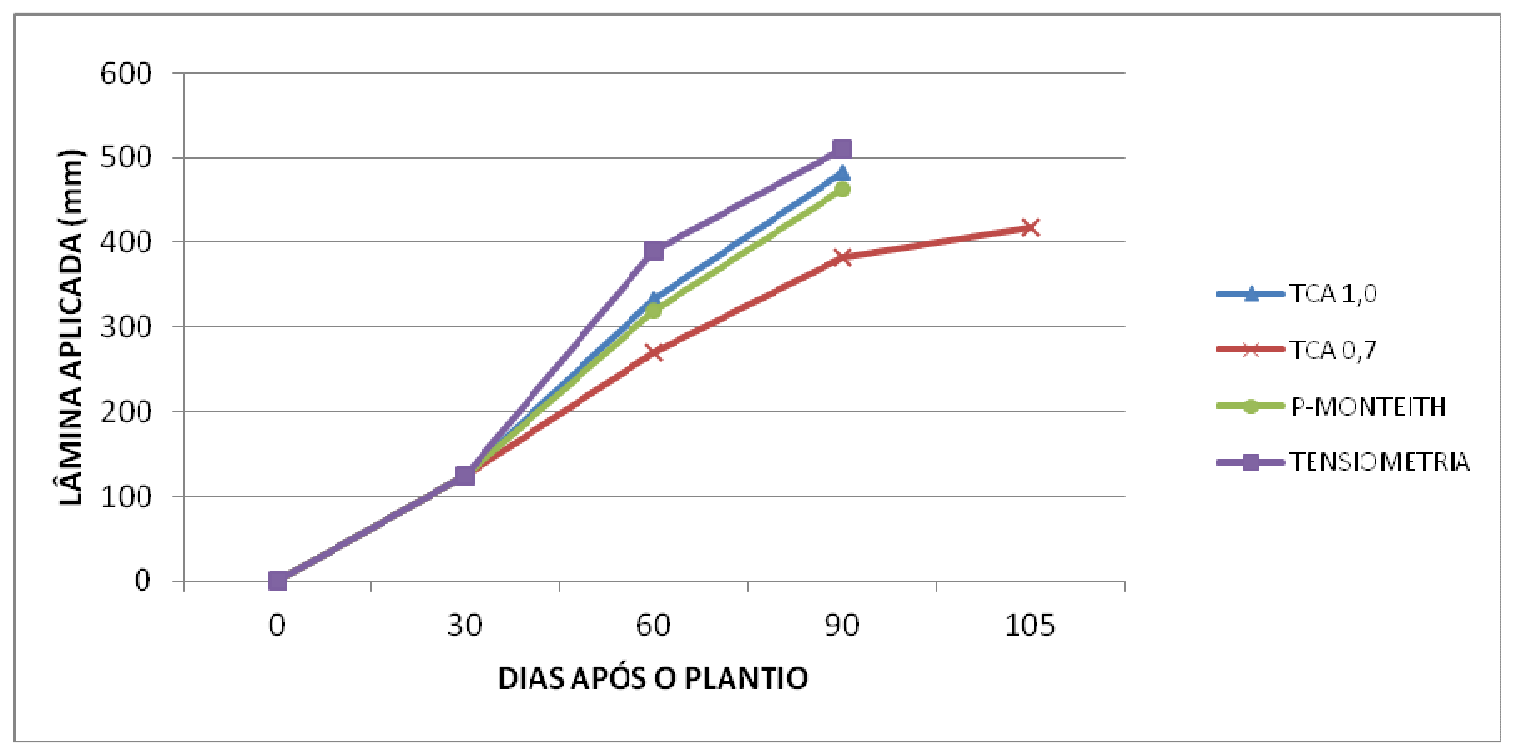

Figura 2. Lâminas totais aplicadas para os diferentes manejos de irrigação.

Com relação ao ciclo fenológico, observou-se que as cultivares nos manejos M1, M2 e M3 apresentaram desenvolvimento uniforme, sendo colhidas aos 90 dias após o transplantio (DAT), enquanto que as do manejo M4 foram colhidas aos 105 DAT, como observado na figura 2, fato provavelmente influenciado pela aplicação da lâmina de água reduzida, promovendo o estresse hídrico das plantas nesse tratamento, resultando em diminuição da produção total e da produção comercial das cultivares. Reghin et al. (2006) relataram que fatores como a menor variação térmica e maior retenção de água no solo em cultivo de cebola na palha, contribuem para o prolongamento do desenvolvimento vegetativo. Avaliando níveis de água no solo, Lima et al. (2006) observaram que o conteúdo de água no solo não exerceu 
efeito significativo sobre a produção de matéria seca da parte aérea e de bulbos de cebola em casa de vegetação.

Pela tabela 1 observa-se que a eficiência de uso de água (EUA), apresenta valores de 92,62 $\mathrm{Kg} \mathrm{ha}^{-1} \mathrm{~mm}^{-1}$ para o manejo M4, 104,92 $\mathrm{Kg} \mathrm{ha}^{-1} \mathrm{~mm}^{-1}$ para o manejo M1, 107,22 Kg ha${ }^{1} \mathrm{~mm}^{-1}$ para o manejo M3 e 100,23 $\mathrm{Kg} \mathrm{ha}^{-1} \mathrm{~mm}^{-1}$ para o manejo M2. Verifica-se, ainda, que o tratamento com maior lâmina bruta aplicada (M2), apresentou valor da EUA inferior ao dos tratamentos M1 e M3, que corresponde a 93,50 \% do encontrado para o melhor manejo (M3). Deve-se ressaltar que a obtenção de cebola de classe superior proporciona maior rentabilidade comercial e maior aceitação no mercado brasileiro, considerado por Reghin et al. (2006), um indicador da alta qualidade de produção alcançada.

Tabela 1. Produtividade comercial, percentual de produtividade, lâmina bruta de irrigação, eficiência de uso de água (EUA) e percentual de classe de bulbos. Juazeiro-BA, 2009.

\begin{tabular}{|c|c|c|c|c|c|c|c|c|}
\hline \multirow{2}{*}{$\begin{array}{c}\text { Manejos } \\
\text { de } \\
\text { Água }\end{array}$} & \multirow{2}{*}{$\begin{array}{c}\text { Prod. } \\
\text { Comercial } \\
\text { Mg.ha }^{-1}\end{array}$} & \multirow{2}{*}{$\begin{array}{l}\text { Percentual } \\
\qquad \%\end{array}$} & \multirow{2}{*}{$\begin{array}{l}\mathrm{L} . \\
\text { bruta } \\
\mathrm{mm}\end{array}$} & \multirow{2}{*}{$\begin{array}{l}\text { EUA } \\
\mathrm{Kg} \mathrm{ha}^{-1} \\
\mathrm{~mm}^{-1}\end{array}$} & \multicolumn{4}{|c|}{ Classe de bulbos \% } \\
\hline & & & & & $\mathrm{Cx} 4$ & $\mathrm{Cx} 3$ & $\mathrm{Cx} 2$ & $\mathrm{Cx} 1$ \\
\hline M1 & $46,25 \mathrm{ab}$ & 90 & 463,47 & 104,92 & 4,60 & 76,91 & 18,49 & 4,89 \\
\hline M2 & $52,03 \mathrm{a}$ & 100 & 535,63 & 100,23 & 9,13 & 78,13 & 12,74 & 3,09 \\
\hline M3 & $49,76 \mathrm{a}$ & 96 & 483,49 & 107,22 & 10,91 & 74,34 & 14,75 & 3,99 \\
\hline M4 & $38,17 \mathrm{~b}$ & 72 & 418,68 & 92,62 & 4,90 & 76,32 & 18,78 & 1,57 \\
\hline $\mathrm{CV}(\%)$ & 21,35 & & & & & & & \\
\hline
\end{tabular}

Mauroelli et al. (2008) trabalhando com cebola, encontraram valores crescentes da EUA para a diminuição da lâmina de irrigação aplicada. Na agricultura irrigada, a elevação e a determinação dos níveis da EUA são complexas e requerem conhecimento e considerações interdisciplinares, porém, o manejo adequado da irrigação permite elevar esses valores. Os resultados obtidos sugerem que a opção por um método de manejo deve basear-se, preferivelmente, na análise conjunta da EUA e da qualidade comercial do produto obtido.

Verifica-se, na Tabela 2, que não houve efeito de interação entre os manejos de água e as cultivares de cebolas avaliadas. Os tratamentos de reposição de água pelo manejo M1, M2 e M3 não apresentaram diferença estatística entre si para a variável produção total, entretanto o manejo com menor aplicação de lâmina (M4) diferiu estatisticamente dos demais, apresentando valores inferiores para esta variável. 
Tabela 2. Resultados médios de produtividade total; produtividade comercial; ácido pirúvico e sólidos solúveis de cultivares de cebola, submetidas a diferentes manejos de água. Juazeiro - BA, 2009. (Mean results of total yield ; marketable yield, pyruvic acid and soluble solids of onion cultivars, submitted to different water management. Juazeiro-BA, 2009).

\begin{tabular}{lcccc}
\hline TRATAMENTOS & $\begin{array}{c}\text { Produtividade } \\
\text { Total } \\
\left(\text { ton.ha }^{-1}\right)\end{array}$ & $\begin{array}{c}\text { Produtividade } \\
\text { Comercial } \\
\left(\text { ton.ha }^{-1}\right)\end{array}$ & $\begin{array}{c}\text { Ácido Pirúvico } \\
\left(\mu \text { moles.mL }{ }^{-1}\right)\end{array}$ & $\begin{array}{c}\text { SS } \\
\left({ }^{\circ} \text { Brix }\right)\end{array}$ \\
\hline $\begin{array}{l}\text { Manejos de água } \\
\text { M1 Penman- }\end{array}$ & & & & \\
Montheith & $48,63 \mathrm{a}$ & $46,25 \mathrm{ab}$ & $3,37 \mathrm{a}$ & $9,89 \mathrm{ab}$ \\
M2 Tensiometria & $53,69 \mathrm{a}$ & $52,03 \mathrm{a}$ & $3,30 \mathrm{a}$ & $9,62 \mathrm{bc}$ \\
M3 TCA 100\% & $51,84 \mathrm{a}$ & $49,76 \mathrm{a}$ & $3,35 \mathrm{a}$ & $10,17 \mathrm{a}$ \\
M4 TCA 75\% & $38,78 \mathrm{~b}$ & $38,17 \mathrm{~b}$ & $2,96 \mathrm{a}$ & $9,2 \mathrm{c}$ \\
\hline CV $(\%)$ & 20,47 & 21,35 & 17,65 & 5,79 \\
\hline Cultivares & & & & \\
C1 IPA -11 & $44,17 \mathrm{~cd}$ & $41,85 \mathrm{~cd}$ & $3,4 \mathrm{a}$ & $10,81 \mathrm{~b}$ \\
C2 IPA -10 & $40,80 \mathrm{~d}$ & $39,17 \mathrm{~d}$ & $3,29 \mathrm{a}$ & $11,72 \mathrm{a}$ \\
C3 ALFA SF & $48,27 \mathrm{bc}$ & $46,7 \mathrm{bc}$ & $3,35 \mathrm{a}$ & $9,83 \mathrm{c}$ \\
C4 SERENA & $54,83 \mathrm{a}$ & $53,42 \mathrm{a}$ & $2,79 \mathrm{~b}$ & $7,74 \mathrm{e}$ \\
C5 ANTARES & $53,11 \mathrm{ab}$ & $51,66 \mathrm{a}$ & $3,38 \mathrm{a}$ & $8,5 \mathrm{~d}$ \\
\hline CV $(\%)$ & 10,36 & 11,30 & 14,94 & 5,66 \\
\hline
\end{tabular}

*Média seguidas de mesma letras, não diferem entre si pelo teste de Tukey a $5 \%$ de probabilidade. (Means followed by same letters are not different by the Tukey test at $5 \%$ of probability).

Os resultados apresentados na Tabela 2 demonstram, ainda, que os métodos de manejos de irrigação estudados não afetaram a concentração de ácido pirúvico dos bulbos para as cultivares avaliadas; contudo, o híbrido Serena (C4), apresentou concentração de ácido pirúvico estatisticamente inferior às demais $\left(2,79 \mu \mathrm{mol} \cdot \mathrm{mL}^{-1}\right)$, atendendo às exigências do mercado internacional em até 3,00 $\mu \mathrm{mol} . \mathrm{mL}^{-1}$ (Santos et al., 2003), classificadas como de pungência muito baixa ou cebola super doce. Avaliando pungência de cebolas em Mossoró RN, Grangeiro (2008) encontrou valores de ácido pirúvico para a cultivar Vale Ouro IPA-11 e Alfa São Francisco, respectivamente de 7,60 e 7,93 $\mu \mathrm{mol} . \mathrm{g}^{-1}$.

Os manejos de irrigação interferiram nos valores encontrados para a variável sólidos solúveis (SS), como pode ser observado na Tabela 2, destacando-se com maiores valores de ${ }^{\circ}$ Brix, os manejos M1 e M3, que não apresentaram diferença estatística significativa entre si. Entretanto, dentre as cultivares estudadas, os valores de ${ }^{\circ}$ Brix variaram de 8,5 a 11,72, demonstrando semelhança aos encontrados por Grangeiro $(2008)$ para as cultivares Vale Ouro IPA-11 e Alfa São Francisco, respectivamente 10,61 e 9,18, e coincidindo com os resultados obtidos por Araújo et al. (2004) para a cebola Franciscana IPA-10 em cultivo orgânico.

Enciso et al. (2009), analisando duas estratégias de manejo de irrigação para cebola, observaram não haver uma relação distinta entre o nível de pungência e concentração de sólidos solúveis ( ${ }^{\circ}$ Brix), não existindo relatos na literatura sobre essa condição. Contudo, Quandir et al. (2005), relataram que em trabalhos conduzidos com cebola na Austrália, observou-se um aumento da pungência em solos úmidos quando comparados a condições de irrigação com menor freqüência ou deficitárias. 
Na Figura 3 está apresentada uma resposta quadrática entre a produção total $\left(\mathrm{t}\right.$ ha $\left.{ }^{-1}\right) \mathrm{e}$ a lâmina total aplicada, com a maior produtividade de 53,69 $\left(\mathrm{t} \mathrm{ha}^{-1}\right)$ para o manejo com maior lâmina aplicada (M2).

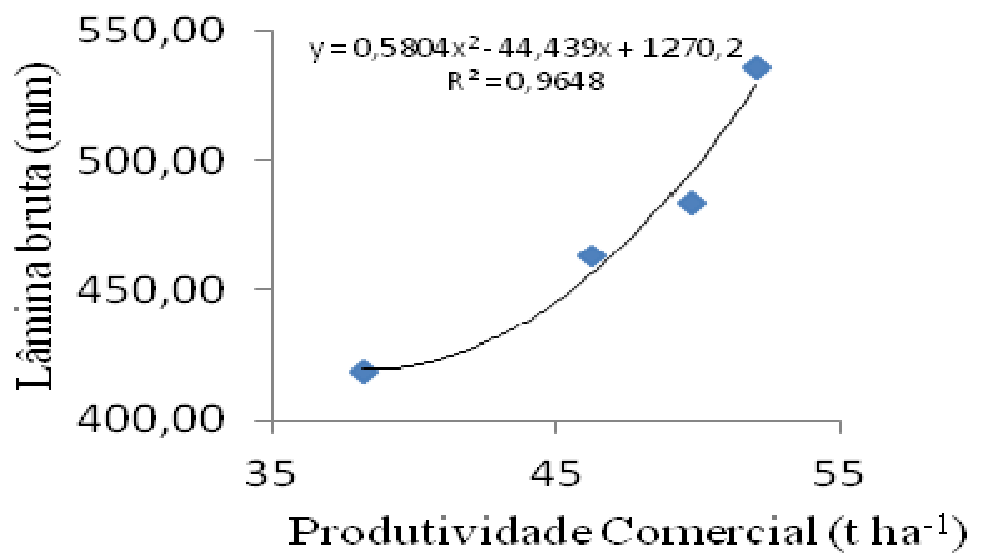

Figura 3. Produtividade de cultivares de cebola em função das lâminas totais aplicadas

Enciso et al. (2009), avaliando o uso da irrigação por gotejamento subsuperficial em cebola, não observaram reduções de produtividade pela aplicação de lâminas de irrigação baseada nos percentuais de 100 e $75 \%$ da ETc. Contudo, estabelecendo diferentes níveis de tensão de água no solo, relataram resultados de produtividade superior para aqueles acima de $30 \mathrm{kPa}$, condição em que os fenômenos de capilaridade assumem grande importância na determinação do potencial mátrico, especialmente tamanho e disposição dos poros (Nascimento et al., 2010), com o que concordam Shock et al. (2000) para a cultura da cebola, com reduções significativas para tensões acima de $-50 \mathrm{kPa}$. Analisando o desempenho produtivo das cultivares, apresentado na Tabela 2, observa-se que as cultivares Serena (C4) e Antares (C5) diferiram estatisticamente das demais para a variável produção comercial, destacando-se respectivamente com 53,42 e 51,66 ton.ha ${ }^{-1}$. Com relação à variável produção total, a cultivar $\mathrm{C} 4$, novamente se destacou com um desempenho produtivo de 54,83 ton. ha $^{-1 \text {, }}$ contudo não apresentando diferença estatística para os valores encontrados com a cultivar C5 de 53,11 ton.ha ${ }^{-1}$. Esta cultivar, por sua vez, teve um comportamento produtivo estatisticamente semelhante ao da cultivar Alfa São Francisco com 48,27 ton.ha ${ }^{-1}$. Observa-se, ainda, que a cultivar IPA $10(\mathrm{C} 2)$, apresentou produtividade inferior às demais $\left(40,80\right.$ ton.ha ${ }^{-}$ $\left.{ }^{1}\right)$, não diferindo estatisticamente da cultivar IPA $11 \mathrm{com} 44,17$ ton.ha ${ }^{-1}$. Esses valores demonstram uma superioridade na produtividade da cebola com o sistema de irrigação por gotejamento, em relação à média no Submédio São Francisco, ligeiramente superior a 20 ton.ha ${ }^{-1}$. Costa et al. (2003), avaliando cultivares de cebola suaves em Juazeiro, BA, obtiveram produção total e comercial respectivamente de 74,75 e 61,11 ton.ha ${ }^{-1}$, para o genótipo de cebola TPC 91923, enquanto que Souza et al. (2008), não observaram variabilidade produtiva em Petrolina e Juazeiro, entre as cultivares de cebola Alfa São Francisco e o híbrido Granex 429. Condição diferente da encontrada por Duarte et al. (2003), na qual o referido híbrido apresentou comportamento produtivo, estatisticamente inferior à IPA 11. No entanto, Resende et al. (2003) obtiveram resultado superiores para as cultivares híbridas Granex 33 e Superex, quando comparada respectivamente as variedades Pira Ouro e Alfa São Francisco, esta última avaliada no presente trabalho. Resende et al. (2007) encontraram resultado superior para a cultivar híbrida Bucanner quando comparada às variedades de cebola Baia periforme, Bola precoce e Red criole, reforçando a superioridade 
das cultivares híbridas sobre as cultivares tradicionais, que propiciam uma maior homogeneidade no desenvolvimento das plantas no campo, reduzindo a produção de bulbos de baixo valor comercial. Verifica-se que o percentual de bulbos não comerciais para as cultivares $\mathrm{C} 1$ e $\mathrm{C} 2$, foram os maiores com 5,32 e 4,99\%, diferentemente das cultivares $\mathrm{C} 3$, C5 e C4, que apresentaram percentuais respectivamente de 3,25, 2,73 e 2,57\% (Figura 4), inferiores àqueles encontrados por Duarte et al. (2003) para cebola Vale Ouro IPA 11 e Franciscana IPA 10 (12 e 7\%), Souza et al. (2008) para cultivares Alfa São Francisco e Vale Ouro IPA 11 (33,15 e 14,45\%) e Costa et al. (2008) para Alfa São Francisco (19,68\%).

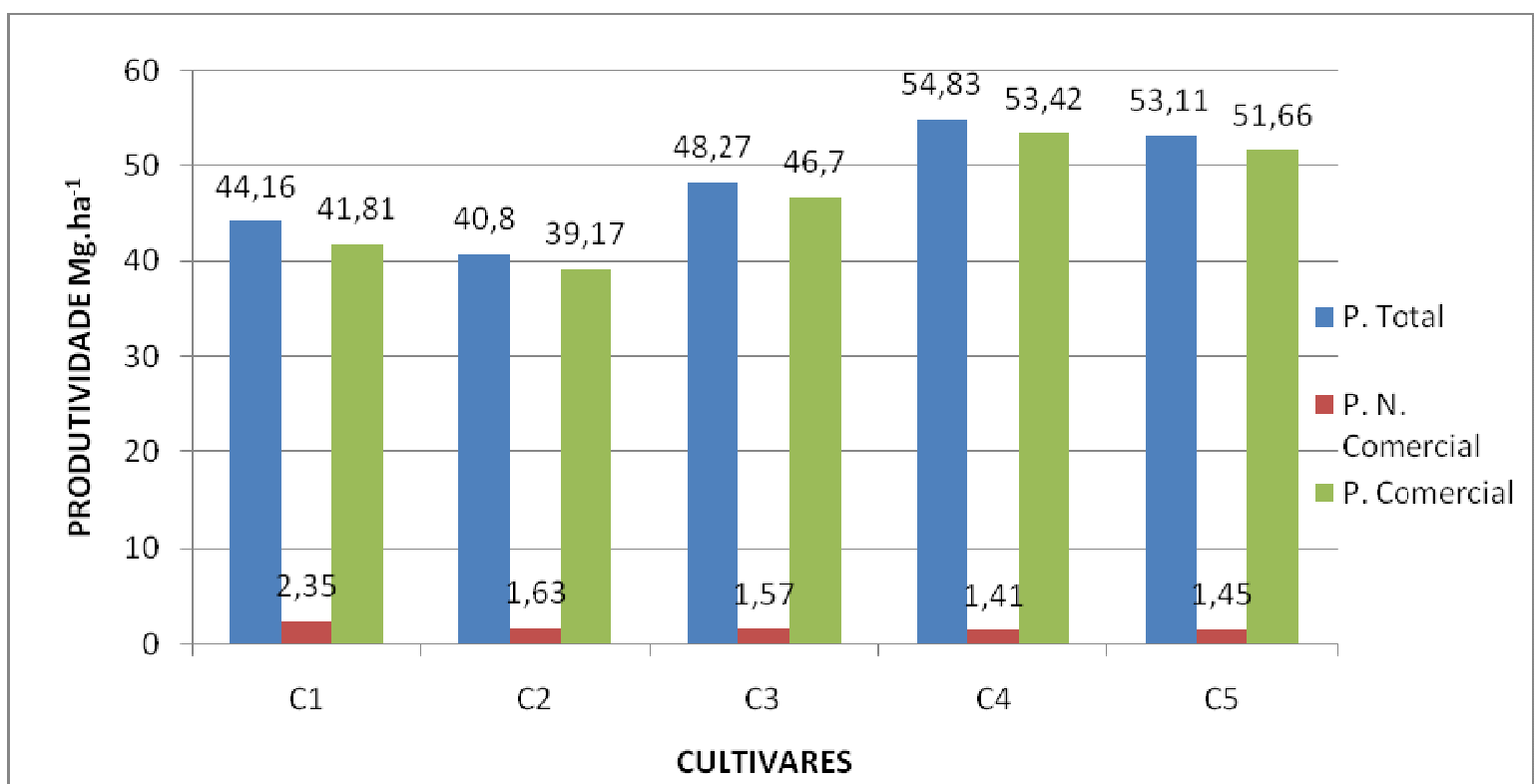

Figura 4. Produtividade total, comercial e não comercial de cultivares de cebola, sob diferentes manejos da irrigação. ....

\section{CONCLUSÕES}

Para as condições experimentais, o híbrido Serena se destacou dentre as demais por apresentar desempenho qualitativo e quantitativo superior. O método de manejo de irrigação baseado na aplicação de água com base em $70 \%$ da evaporação do tanque classe A resultou na menor produtividade total e comercial.

\section{REFERÊNCIAS BIBLIOGRÁFICAS}

ARAÚJO, W.F.; COSTA, S.A.A.; SANTOS, A.E. Comparação entre métodos de estimativa da evapotranspiração de referência (ETo). Revista Caatinga, Mossoró, v.20, n.4, p.84-88, 2007.

CÂMARA, M.J.T.; NEGREIROS, M.Z.; MEDEIROS, J.F.; NETO, F.B.; JÚNIOR, A.P.B. Produção e qualidade de melão amarelo influenciado por coberturas do solo e lâminas de irrigação no período chuvoso. Ciência Rural, v. 37, n. 1, p. 58-63, 2007. 
COSTA, N.D.; SANTOS C.A.F.; FARIA, C.M.B.; LIMA, M.A.C.; ASSIS, J.S. 2003. Avaliação de genótipos de cebola suave no Submédio São Francisco. In: CONGRESSO BRASILEIRO DE HORTICULTURA, 43, Anais... Recife, Associação Brasileira de Horticultura, 2003.

COSTA, N.D.; PINTO, J.M.; SANTOS, C.A.F.; SANTOS, G.M., SANTOS, C.R., BANDEIRA, G.R.L. 2004. Comparação de métodos de irrigação em cebola no Vale do São Francisco, In: CONGRESSO BRASILEIRO DE HORTICULTURA, 44, Anais... Campo Grande, Associação Brasileira de Horticultura, 2004.

COSTA, N.D.; ARAUJO. J.F.; SANTOS. C.A.F.; RESENDE, G.M.; LIMA, M.A.C. 2008. Desempenho de cultivares de cebola em cultivo orgânico e tipos de solo no Vale do São Francisco. Horticultura Brasileira v. 26, p. 476-480, 2008

DOORENBOS, J.; KASSAM, A.H. Efeito da água no rendimento das culturas. Campina Grande: Tradução Gheyi H.R. e outros, UFPb FAO. 221 p. 2000.

DUARTE, R.L.R.; VELOSO, M.E.C.; MELO, F.B.; ATHAYDE SOBRINHO, C.; RIBEIRO, V.Q.; SILVA, P.H.S.. Produtividade de cultivares de cebola no Semi-árido piauiense.

Horticultura Brasileira, Brasília, v. 21, n. 1, p. 34-36, 2003.

ENCISO, J.; WEIDENFELD, B.; JIFON, J.; NELSON, S. Onion yield and quality response to two irrigation scheduling strategies. Scientia Horticulturae v.120, p.301-305, 2009.

FERNANDES, E.J. Comparação entre três métodos para estimar lâminas de irrigação. Irriga, v.13, n.1, p. 36-46, 2008.

GRANGEIRO, L.C.; SOUZA, J.O.; AROUCHA, E.M.M.; NUNES, G.H.S.; SANTOS, G.M. Características qualitativas de genótipos de cebola. Ciências e Agrotecnologia, Lavras, v. 32, n. 4, p. 1087-1091, 2008.

GONZÁLEZ, A.M.; BONACHELA, S.; FERNÁNDEZ, M.D. Regulated deficit irrigation in green bean and watermelon greenhouse crops. Scientia Horticulturae. v. 122, p.527-531. 2009.

HORTIBRASIL, INSTITUTO BRASILEIRO DE QUALIDADE EM HORTICULTURA. Serviços, Classificação, Cebola. Disponível em:

$<$ http://www.hortibrasil.org.br/classificacao/cebola/arquivos/classes.html > Acesso em: $12 \mathrm{de}$ fevereiro de 2010.

KELLER, J.; KARMELI, D. Trickle irrigation design. Rain Bird Sprinkler Manufacturing Corporation, 133 p. 1975.

LIMA, M.D.B.; BÜLL, L.T.; FILHO, H.G.. Índices fisiológicos e absorção de nutrientes pela cultura da cebola submetida a condições de salinidade e estresse hídrico. Irriga, v.11, n.3, p. 356-366. 2006. 
Manual de Adubação e Calagem Para o Estado da Bahia. Salvador, CEPLAC, EMATERBA, EMBRAPA, EPABA, NITROFÉRTIL. 2 ed., 176 p. 1989.

MAROUELLI, W.A.; COSTA, E.L.; SILVA, H.R. Irrigação na cultura da cebola. Embrapa Hortaliças, 17 p. Circular Técnica 37, 2005.

MAROUELLI, W.A. Irrigação em campos de produção de sementes de hortaliças. Embrapa hortaliças, 16 p. Circular técnica 52. 2007

MAROUELLI, W.A. Tensiômetros para o controle da irrigação em hortaliças. Brasília: EMBRAPA/CNPH.15p. Circular técnica, 57, 2008.

MAROUELLI, W.A.; SILVA, H.R.; ABDALLA, R.P.; MADEIRA, N.R.. Necessidade de água da cultura da cebola em sistemas de plantio direto e convencional. 2008. Disponível em http://www.intasgo.gov.ar/ambiente/Trabajos/22.pdf. Acesso em 10 de setembro de 2010.

MENDONÇA, J.C.; SOUSA, E.F.; ANDRÉ, R.G.B.; BERNARDO, S. Coeficientes do Tanque Classe A, para estimativa de evapotranspiração de referência em Campo dos Goytacazes, RJ. Revista Brasileira de Agrometeorologia, v. 14, n. 1, p. 123-128, 2006.

NASCIMENTO, P.S.; BASSOI, L. H.; PAZ, V. P. S.; VAZ, C. M. P.; NAIME, J. M.; MANIERI, J. M. Estudo comparativo de métodos para a determinação da curva de retenção da água do solo. Irriga, v. 15, n. 2, p. 193-207, 2010.

QUANDIR M, BOULTON A, EKMAN J, HICKEY M, HOOGERS R. Influence of drip irrigation on onion yield \& quality. IREC Farmers' Newsletter, v.170, p. 29-31, 2005.

REGHIN, M.Y.; OTTO, R.F.; OLINIK, J.R.; JACOBY, C.F.S. Produção de cebola sobre palhada a partir de mudas obtidas em bandejas com diferentes números de células.

Horticultura Brasileira, v.24, n. 4, p. 414-420, 2006.

RESENDE, G.M.; CHAGAS, S.J.R.; PEREIRA, L.V. Características produtivas de cultivares de cebola no Sul de Minas Gerais. Horticultura Brasileira, v.21, n. 4, p.722-725, 2003.

RESENDE, M. \& OLIVEIRA, A.C. Comparação de diferentes estratégias de programação de irrigação suplementar em milho. Revista Brasileira de Milho e Sorgo, v.4, n.2, p.205-214, 2005.

RESENDE, J.T.V.; PIRES, D.B.; CAMARGO, L.K.P.; MARCHESE, A. Desempenho produtivo de cultivares de cebola em Guarapuava, Paraná. Ambiência - Revista do Setor de Ciências Agrárias e Ambientais v.3, n. 2, p. 193-199, 2007.

SANTOS, C.A.F.; LIMA, M.A.C.; COSTA, N.D.; LEITE, W.M.; ROQUE, I.M.B. Seleção indireta via teor de sólidos solúveis totais para identificação de bulbos de cebola com baixa pungência. In: CONGRESSO BRASILEIRO DE HORTICULTURA, 43, Anais...Recife, 2003. 
SCHWIRMMER, S.; WESTON, W. J.. Enzimatic development of pyruvic acid as a measure of pungency. Journal Agricultural Food Chemistry, v.9, p.301-304, 1961.

SOUZA, J.O.; GRANGEIRO, L.C.; SANTOS, G.M.; COSTA, N.D.; SANTOS, C.A.F.; NUNES, G.H.S. Avaliação de genótipos de cebola no Semi-Árido Nordestino. Horticultura Brasileira, v.26, n. 1, p.097-101, 2008.

SHOCK, C.C., FEIBERT, E.B.G.; SAUNDERS, L.D.; Irrigation criteria for drip-irrigated onions. Hortscience. Alexandria, v.35, p.63-66, 2000. 